\title{
Microfistulas Causing Diverse Regional Ischemia: Consecutive Inferior and Lateral ST-Elevation Myocardial Infarction
}

\author{
Tufan Çınar, $\mathrm{MD}^{{ }^{*}}$; Yavuz Karabağ, $\mathrm{MD}^{2}$; İbrahim Rencuzogullari, $\mathrm{MD}^{2}$; Metin Cağdaş, $\mathrm{MD}^{2}$ \\ ${ }^{1}$ Health Sciences University, Sultan Abdülhamid Han Training and Research Hospital, Istanbul, Turkey \\ ${ }^{2}$ Kafkas University Medical School, Department of Cardiology, Kars, Turkey
}

\begin{abstract}
Coronary artery fistulas (CAFs) are described as abnormal communications between a coronary artery and cardiac chambers, or other vascular structures. The two types of CAFs are defined as type I (singular fistula) and type II (microfistulas). Even though various electrocardiographic changes have been previously described in CAF patients, coronary-artery microfistulas causing STsegment elevation in diverse locations have not been reported. We describe a case report of an adult patient who presented with acute inferior myocardial infarction due to coronary-artery microfistulas. During the hospital stay, the patient re-experienced chest pain, and control electrocardiography revealed ST-segment elevation in the I and AVL leads along with reciprocal ST-segment depression in the inferior precordial leads. Although CAFs are clinically rare, they can have important clinical consequences. Microfistulas should be kept in mind as a cause of ST elevation myocardial infarction in some patients.

Keywords: Coronary artery fistula, Diverse ischemia, ST elevation myocardial infarction

Cite this article as: Çınar T, Karabağ Y, Rencuzogullari I, Cağdaş M. Microfistulas Causing diverse regional ischemia: consecutive inferior and lateral ST-elevation myocardial infarction. Arch Iran Med. 2020;23(10):704-706. doi: 10.34172/aim.2020.89.
\end{abstract}

Received: September 30, 2018, Accepted: May 14, 2019, ePublished: October 1, 2020

\section{Introduction}

Coronary artery fistulas (CAFs) are described as abnormal communications between a coronary artery and cardiac chambers, or other vascular structures. ${ }^{1}$ The incidence of CAFs is $0.002 \%$ in the general population, and they account for $0.2-0.4 \%$ of all congenital heart anomalies. CAFs are classified into two types. ${ }^{2,3}$ Type I (singular fistula) is defined as an abnormal communication which directly links one or more coronary arteries to a heart chamber or to major thoracic vessels, whereas type II (microfistulas) is defined as multiple micro-connections between a coronary artery and the left ventricle. Most fistula patients are usually asymptomatic, but they may experience dyspnea, fatigue, palpitation, and angina symptoms. Thromboembolisms, heart failure, bacterial endocarditis, myocardial ischemia, rupture of an aneurysm, and sudden death have been reported as complications related to CAFs. ${ }^{3}$ Although various ECG changes have been previously described in CAF patients, coronary-artery microfistulas causing STelevation myocardial infarction in diverse locations have not been reported. Here, we describe a case report of an adult patient who presented with acute inferior myocardial infarction due to coronary-artery microfistulas. Moreover, during the hospital stay, the patient re-experienced chest pain, and control electrocardiography revealed ST elevation in the I and AVL leads along with reciprocal ST depression in the inferior precordial leads.

\section{Case Report}

A 48-year-old male was admitted to the emergency service with acute onset chest pain. The pain was located retrosternally, was squeezing in character, and radiated to the jaw and left shoulder. The patient's baseline electrocardiogram (ECG) revealed a normal sinus rhythm and ST-segment elevation in the inferior precordial leads along with reciprocal ST-segment depression in the DI and AVL leads (Figure 1A). The patient had a history of hypertension, and his blood pressure was $117 / 68 \mathrm{~mm} / \mathrm{Hg}$. Other physical findings on admission were unremarkable except for pale, dewy skin. Laboratory analysis revealed that the following cardiac enzymes were slightly elevated: creatine kinase-myocardial band (36 IU/L) and troponin I $(0.11 \mathrm{ng} / \mathrm{mL})$. Urgent coronary angiography was performed, which revealed diffuse and multiple coronaryarterial microfistulas originating from the distal segments of both the left anterior descending artery and circumflex arterial systems and terminating in the left ventricle without any stenosis in the epicardial coronary arteries (Supplementary Video 1). Because of the multiplicity and small caliber of the fistulas, conservative treatment was planned for the patient. While being followed up in the intensive-care unit, the patient re-experienced chest 
pain that lasted for 25 minutes and afterward terminated spontaneously. Control ECG showed ST-segment elevation in the I and AVL leads along with reciprocal STsegment depression in the inferior precordial leads (Figure 1B). Because the patient had no known diseases except hypertension, we investigated the coagulation defects that may be associated with ST elevation myocardial infarction, but all of the results were negative. After coronary angiography, an exercise stress test was performed, showing low risk (Duke treadmill score: 7). The patient did not have pain again and was discharged with daily $100 \mathrm{mg}$ metoprolol and $100 \mathrm{mg}$ acetylsalicylic acid.

\section{Discussion}

Coronary artery microfistulas are rare coronary anomalies that may have clinical and hemodynamic consequences. In an earlier study, coronary microfistulas were reported to account for $18 \%$ of all fistulas. ${ }^{2}$ Although most fistula patients are asymptomatic, ${ }^{3}$ the incidence of angina was not uncommon in previous studies. ${ }^{4.5}$ Similarly, the patient in our case presented to the emergency service with angina.

The probable mechanisms of myocardial ischemia induced by CAFs are thought to result from a shuntingand-steal phenomenon in the coronary flow. The decrease of blood flow in the epicardial arteries may result in ischemic symptoms. This theory may also be valid for our patient. However, this may not be the only reason, as in our patient, although the epicardial artery was not completely cut off, ST-segment elevation was observed in the ECG. Therefore, in our patient, in addition to the
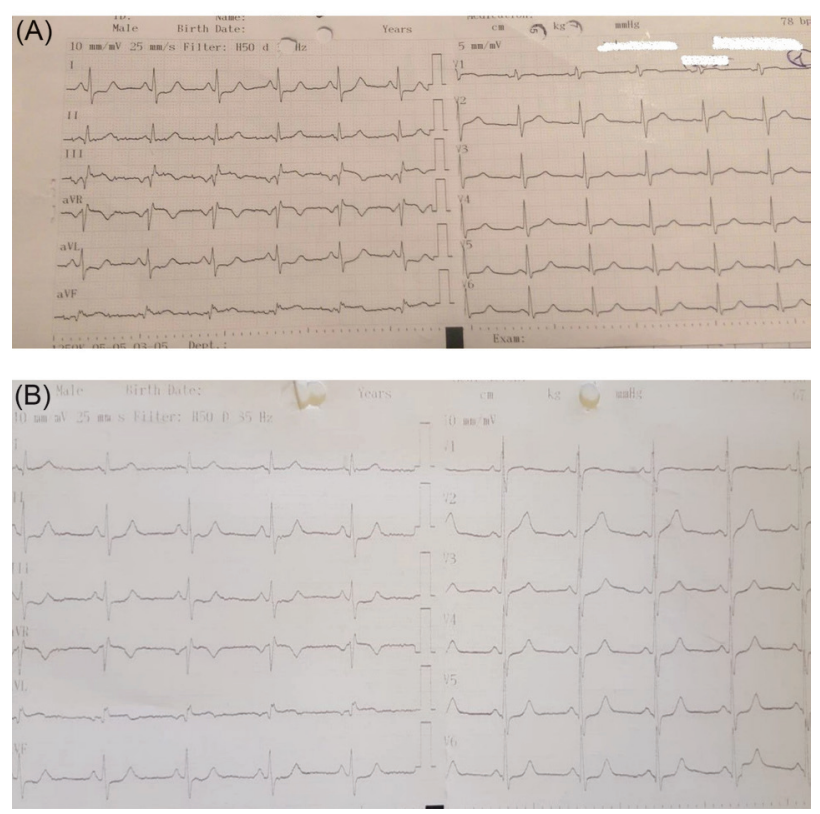

Figure 1. (A) Electrocardiogram image showing ST-segment elevation in the inferior leads and reciprocal ST-segment depression in the I and AVL leads. (B) Electrocardiogram image showing ST-segment elevation in the I and AVL leads and reciprocal ST-segment depression in the inferior leads. steal phenomenon, additional histopathological changes may have developed. Even though coronary blood flow, as similar to syndrome $\mathrm{X}$ patients, is present in congenital microfistulas patients, the coronary-flow dynamics may have changed as a consequence of histopathological changes. Possible histopathological changes may include the development of endothelial dysfunction, stimulation of inflammatory processes, and alteration of the wall tension. Endothelial dysfunction may lead to impaired production of vasoactive substances, impaired coronaryflow responses, and abnormalities of adenosine receptors or their metabolism, resulting in impaired coronary vasodilatation and myocardial ischemia. ${ }^{6-8}$ In our patient, in addition to the steal phenomenon, these histopathological changes may have developed and may have caused complete interruption in the coronary perfusion.

Hemodynamically significant large coronary fistulas can be closed by surgical or percutaneous-catheter techniques. Microfistulas, however, are not suitable for surgical or percutaneous occlusion due to their small size and large number. In such patients, medical treatment is recommended. The clinical condition of our patient improved with treatment by the beta-blocker metoprolol. Beta-blockers may be effective in these patients by reducing heart rate, prolonging the coronary-diastolic perfusion time, decreasing myocardial oxygen demands, improving myocardial energetics, up-regulating beta-adrenergic receptors, and reducing myocardial oxidative stress. ${ }^{9}$

In conclusion, although CAFs are clinically rare, they can have important clinical consequences. Coronary hemodynamics may be more deteriorated than it appears in patients with microfistulas. This may be due to histopathological changes in addition to the visually present micro-connections. Beta blockers may be an appropriate treatment in such symptomatic coronaryartery microfistula patients. Microfistulas should be kept in mind as a cause of ST elevation myocardial infarction in some patients.

\section{Authors' Contribution}

TÇ and IR planned the study. YK and MÇ collected the data. TÇ and YK analyzed the data. TÇ, YK, IR and MÇ performed the literature search. TÇ wrote the paper. IR and $M C$ made the critical revision of the paper. All authors have contributed significantly to the manuscript to be published.

\section{Conflict of Interest Disclosures}

All authors declare that they do not have conflict of interest.

\section{Ethical Statement}

A written informed consent was obtained from the patient for publication of this case report. The authors received no financial support for the research, authorship, and/or publication of this article.

\section{Supplementary Materials}

Supplementary Video 1. Coronary angiography image showing multiple coronary arterial microfistulas originating from the distal segments of both the left anterior descending artery and circumflex arterial systems. 


\section{References}

1. Fernandes ED, Kadivar H, Hallman GL, Reul GJ, Ott DA, Cooley DA. Congenital malformations of the coronary arteries: the Texas Heart Institute experience. Ann Thorac Surg. 1992; 54(4):732-40. doi:10.1016/0003-4975(92)91019-6.

2. Chiu CZ, Shyu KG, Cheng JJ, Lin SC, Lee SH, Hung HF, et al. Angiographic and clinical manifestations of coronary fistulas in Chinese people: 15-year experience. Circ J. 2008;72(8):12428. doi: 10.1253/circj.72.1242.

3. Loukas M, Germain AS, Gabriel A, John A, Tubbs RS, Spicer D. Coronary artery fistula: a review. Cardiovasc Pathol. 2015;24(3):141-8. doi:10.1016/j.carpath.2014.01.010

4. Canga Y, Ozcan KS, Emre A, Kul S, Guvenc TS, Durmuş $\mathrm{G}$, et al. Coronary artery fistula: review of 54 cases from single center experience. Cardiol J. 2012;19(3):278-86. doi: 10.5603/cj.2012.0050.

5. Doğan M, Sunman H, Akyel A, Çimen T, Bilgin M, Efe T, et al. Prevalence and clinical features of microfistulas between the coronary artery and left ventricle: single-center experience. Turk Kardiyol Dern Ars. 2014;42(4):332-8. doi:10.5543/ tkda.2014.25936.

6. Quyyumi AA, Cannon 3rd RO, Panza JA, Diodati JG, Epstein SE. Endothelial dysfunction in patients with chest pain and normal coronary arteries. Circulation. 1992;86(6):1864-71. doi:10.1161/01.cir.86.6.1864.

7. Egashira K, Inou T, Hirooka Y, Yamada A, Urabe Y, Takeshita A. Evidence of impaired endothelium-dependent coronary vasodilatation in patients with angina pectoris and normal coronary angiograms. N Engl J Med. 1993;328(23):1659-64. doi:10.1056/NEJM199306103282302.

8. Vrints CJ, Bult H, Hitter E, Herman AG, Snoeck JP. Impaired endothelium-dependent cholinergic coronary vasodilation in patients with angina and normal coronary arteriograms. J Am Coll Cardiol. 1992;19(1):21-31. doi:10.1016/07351097(92)90046-p.

9. López-Sendón J, Swedberg K, McMurray J, Tamargo J, Maggioni $\mathrm{AP}$, Dargie $\mathrm{H}$, et al. Expert consensus document on betaadrenergic receptor blockers. Eur Heart J. 2004;25(15):134162. doi:10.1016/j.ehj.2004.06.002. 